\title{
COOPERATION AND CONFLICT IN THE EVOLUTION OF SIGNAL INTERACTIONS
}

\author{
Michael D. Greenfield \\ Department of Entomology, University of. Kansas, Lawrence, Kansas 66045 \\ KEY WORDS: chorusing, thythm, sexual communication, sexual competition, synchrony
}

\begin{abstract}
Various invertebrate and vertebrate species in which males produce acoustic or bioluminescent signals for long-range sexual advertisement exhibit collective patterns of temporal signal interactions. These patterns range from simple concentrations of signaling during a narrow diel interval to synchronous and alternating interactions entailing precisely timed phase relationships between neighboring individuals. Signals involved in synchrony and alternation are generally produced with rhythms that are under the control of central nervous oscillators. Neighboring individuals effect these interactions via mutual phase delays or phase advances of their oscillators or actual changes in the free-running periods of their oscillators. Both synchrony and alternation may represent adaptations to avoid spiteful behavior or to maximize the ability of a local group to attract females or evade natural enemies. Alternatively, these collective patterns may represent incidental outcomes of competition between males jamming each other's signals. The neural mechanisms that effect signal jamming can be selected for by critical psychophysical factors such as precedence effects. Additional competitive pressures that may generate synchrony, alternation, and other collective patterns of signal interaction include mutual assessment of rivals, evasion of detection by dominant individuals, disruption of communication within courting pairs, and narrowness of the time intervals during which receptive females are present.
\end{abstract}




\section{INTRODUCTION}

In many animal species in which males produce long-range sexual advertisement signals, population densities are often high enough for signaling neighbors to perceive one another. Under such conditions it is common for males to interact mutually by adjusting the timing of their signals. These interactions occur primarily in acoustic $(3,148)$ and bioluminescent signaling $(26,101)$, and they are best known among arthropods, anurans, and birds. Massive choruses of periodical cicadas in North America (4), dawn and evening choruses of various birds and other acoustic animals $(81,158)$, and synchronous flashing at firefly (lampyrid beetle) aggregation trees in Southeast Asia (15) count among the more impressive signal interactions, which one author $(153$, p. 331$)$ has referred to as "great spectacles of the living world." Similar phenomena, perhaps less apparent to human observers, are found in numerous other species, and they involve varying degrees of temporal precision.

Because signal interactions are nearly always associated with individuals in aggregations, the question of their function in the context of social behavior arises $(3,17,63,112)$. Accordingly, the major thrust of this review is coverage of the various hypotheses and studies on the evolution of signal interactions, with emphases on the cooperative and competitive functions that these interactions may serve. To assess these hypotheses and data adequately, though, a proximate understanding of the neuroethological mechanisms controlling signal generation and perception is usually necessary: In many cases the collective pattern of signal interactions can be reduced to a summation of inter-individual stimuli and responses (3), and such processes are likely to be physiologically constrained in some fashion. Therefore, mechanisms are treated as well to afford a more thorough review and evaluation of the evolutionary issues. Fortunately, a wealth of information on controlling mechanisms exists, because most of the initial interest in signal interactions came from neuroethologists. Only recently, however, have explicit evolutionary questions concerning chorusing and related bioluminescent phenomena been posed. Nonetheless, some of these current studies have explicated interactive displays in surprising ways, and in doing so they have revealed critical aspects of sexual communication and sexual selection that would otherwise have remained unrecognized.

\section{FORMATS OF INTERACTIVE DISPLAY}

\section{Levels of Temporal Precision}

The intent of this section is not to provide a rigid framework with which to categorize various formats, but rather to introduce the assorted phenomena to be considered, arranged in a sequence that progresses toward increasing temporal precision of the interactions. 
In a crude fashion, males in many species adjust their activity on a diel basis so that they signal at the same time as their neighbors. This type of collective display has been referred to as a "spree" (145), the temporal equivalent of a (spatial) lek. Such concentrations of signaling within a restricted time interval usually occur close to photoperiodic transitions: e.g. dawn and dusk choruses in birds $(33,81)$, cicadas $(158)$, and acridid grasshoppers (58), calling during the beginning of the night in anurans and various orthopteran insects $(92,145)$, and twilight flashing in lampyrid beetles (87). Unlike all other signal interactions, these collective displays do not necessarily entail mutual perception of signals. The concurrent signaling that characterizes them could be effected by specific, invariant responses to photoperiodic or other environmental cues (32, $58,87)$.

At a higher level of precision, acoustic signalers may engage in "unison bout singing." Here, individuals within a "hearing radius" all sing collectively for several seconds to a few minutes, remain silent for a variable interval, and then repeat the cycle many times during the diel activity period $(2,45,55$, $127,152)$. In some cases, unison bout singing may involve more extensive groups of individuals (3) among which collective signaling is facilitated by a "chain-reaction effect." Within these singing bouts, "leaders," individuals who habitually sing first, can sometimes be distinguished $(23,55,152)$. Comparable events involving chain reactions are known in bioluminescent signalers as well (14).

Among arthropods and anurans that produce rhythmic acoustic or bioluminescent signals, more specialized temporal interactions sometimes occur in which the signals of neighbors are related by a given phase angle $(2,3,26$, 49,148 ). The most striking phenomena, generally termed synchrony and alternation, occur when phase angles approximate $0^{\circ}$ and $180^{\circ}$, respectively. Intermediate phenomena and combinations of synchrony and alternation exist in some species. For example, the participants in a synchronous chorus may only partially overlap their songs $(46,131,138)$, and alternating choruses may be punctuated by occasional occurrences of synchrony $(2,78,130)$. As above, consistent leaders, individuals whose rhythm is slightly advanced relative to their neighbors, may exist among synchronizers $(97,124)$. Alternating species too may include distinctive individuals, those who tend to disrupt the regular pattern by bouts of rapid signaling $(23,79,130,157)$. Signal interactions can also involve the hierarchical nesting of one or more of the above levels within another; e.g. evening choruses and unison bouts may overlie synchrony or alternation (49).

I have chosen to limit this review to interactions involving only the longrange advertisement signals of conspecifics. Consequently, some well-known phenomena such as close-range male-female courtship dialogues found in avian dueting and in the flash communication of lampyrid beetles, hetero- 
specific interactions, typically involving unilateral inhibition, and jamming avoidance responses of electrolocating gymnotiform fish are not considered here.

\section{Communication Channels}

Review of the literature suggests that while signal interactions are widespread among arthropod and vertebrate taxa, they are primarily restricted to certain channels: sound and light (bioluminescence). This may not reflect mere coincidence or sampling bias. Possibly, only acoustic and nocturnal bioluminescent signals are normally transmitted over sufficient distances that neighboring signalers can detect them (39). In fact, the use of alternative channels such as substrate vibration has been interpreted in some cases as an evolutionary shift to avoid heterospecific or conspecific "eavesdroppers" $(9,102)$. Even if intensity exceeds detection thresholds, signal:noise ratios and contrast in other communication channels, (diurnal) reflected light, for example, may not be high enough to select for signal interactions. That is, temporal adjustments by individual signalers may be quite inconspicuous, and conspecific and heterospecific receivers would remain uninfluenced by any alternating or synchronous event.

Additionally, sound and bioluminescence, unlike olfactory signals, are transmitted nearly instantaneously; they rise above perceptual threshold levels suddenly and do not fade out slowly upon termination; and their sources may be localized by a distant receiver (39). The last factor ensures that the signals of individuals retain some integrity and avoid being completely lost in a group's blended emission. Therefore, the fundamental reasons that might favor precise adjustments in signal timing relative to that of a particular neighbor(s) could only be compelling for signalers using these two channels.

\section{RHYTHM GENERATION AND INTERACTIVE ALGORITHMS}

\section{Neural Oscillators}

The precise timing and phase relationships in alternating and synchronous choruses and bioluminescent displays in arthropods and anurans occur in species that produce signals rhythmically. A variety of models have been proposed to account for the general regulation of timing in animals (e.g. see 54). Regulation of the rapid thythms (period $<-10 \mathrm{sec}$ ) under consideration here, however, is probably best described by a neural oscillator model. This model assumes that a pacemaker in the central nervous system (CNS) is responsible for the regular periodicity of effector activity $(26,30,78)$ and that the pacemaker continues whether or not the signaler perceives its own signal 


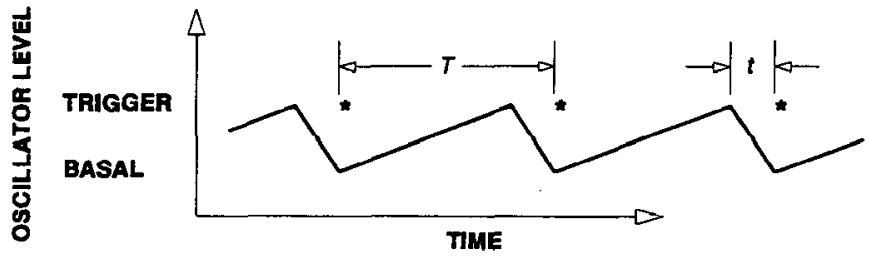

$\boldsymbol{b}$
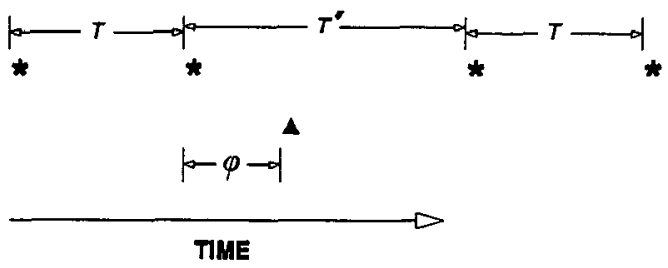

c
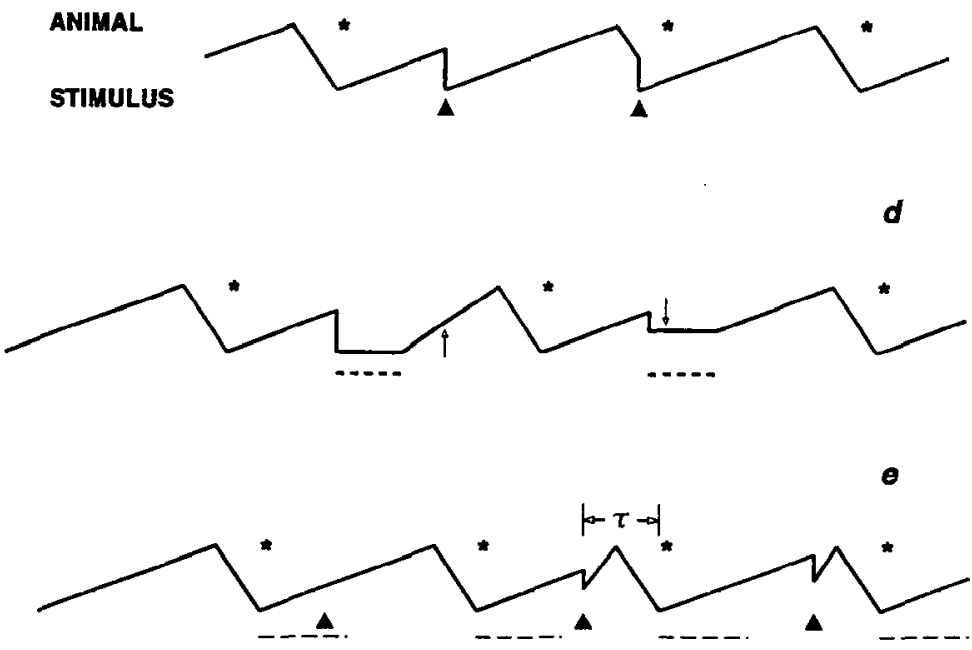

Figure 1 Timing of central nervous oscillators responsible for rhythmic signals in animals. (a) Free-running oscillator showing signal $\left({ }^{*}\right)$, signal period $(T)$, effector delay $(t)$, and basal and trigger levels of the oscillator. $(b)$ Temporal relationships in a rhythmic signal regulated by a phase delay mechanism. $\Delta$ is the stimulus, $\phi$ is the stimulus delay, $(\phi / T) \cdot 360^{\circ}$ is the stimulus phase, and $((T-T) / T)$ - $360^{\circ}$ is the response phase. (c) Phase delay resetting of oscillator by stimulus (adapted from ref. 18). (d) Inhibitory resetting of oscillator by a lengthy stimulus (adapted from ref. 62). After inhibition, retum of oscillator to trigger level is faster due to either a steeper slope $(\uparrow)$ or incomplete resetting $(\downarrow)$. (e) Modification of phase-delay resetting common in anurans. A refractory period (- - - - ), during which the animal is immune to resetting, follows the signal. After the refractory period, the oscillator is reset by stimuli, but then returns very rapidly to the trigger level. $\tau$ is the rebound interval of the oscillator. 


\section{GREENFIELD}

or even produces a signal. These criteria are generally met: Rhythmic effector activity can be elicited by arhythmic electrical stimulation of specific brain loci (74), perceptually deprived animals continue to signal rhythmically (18, 19), and harmonics may be conspicuous in the frequency distribution of signal periods of solo individuals (18). The harmonics are periods approximately $n$ times the modal or preferred length (T), and they represent omission of effector output $n-1$ times in succession.

Under oscillator timing, signal onset necessarily occurs a short time interval $(t ; t \ll T)$ after the signal has been triggered by the CNS pacemaker (Figure 1a). Thus, $t$ is an effector delay, and its length is constrained by the velocity of neural transmission and the duration of effector activation. Inferred measurements of $t$ indicate values ranging from 50 to $200 \mathrm{~ms}(14,16,144)$. Rhythms tend to drift above and below the mean signaling rate to some extent. Such fluctuations may conceivably result from variation in $T$ or $t$. A general statistical method for discerning the source of rhythmic fluctuation has been applied to lampyrid beetle flash rhythms, and the results implicated variation in $T$ as the source (19). Spontaneous phase shifting, an abrupt change in the length of a single period, also occurs in the rhythms of individuals signaling in solo (147). Period lengthening may be more common here, possibly due to upper limits on CNS pacemaker rates that preclude excessive period shortening.

\section{Homoepisodic vs Proepisodic Mechanisms}

Various rhythmic arthropods and anurans interact with remarkable precision considering their high signaling rates. In acoustic Orthoptera and Hemiptera, synchrony may occur between neighbors calling as fast as $5 \sec ^{-1}(47,50,52)$. Because of the effector delay $t$ discussed above, such interactions are all the more intriguing: How is it possible for individuals to adjust their timing given the constraints on effector response imposed by the CNS pacemaker?

Timing adjustments may be effected in either a homoepisodic or a proepisodic fashion (144). In the first case, an individual detects the signal of a neighbor and responds by producing its own signal. Thus, a synchronous event would be generated by a nearly immediate response to the concurrent signal of a neighbor(s). This sort of mechanism must be responsible for the synchronous onsets inherent in unison bout singing, because these bouts do not recur rhythmically. However, homoepisodic mechanisms cannot explain interactions involving many rhythmic signals: The time interval between the signal onsets of synchronizing neighbors is often shorter than a reasonable estimate for $t$ $(16,144)$, and in acoustic signaling it may even be shorter than the duration of time required for sound to travel between the individuals.

Proepisodic mechanisms involve a response to a previous signal(s) of a neighbor that allows the focal male's signal to be produced at a given phase 
angle with respect to the neighbor's concurrent signal. Among synchronizing signalers, two primary types of proepisodic mechanisms have been identified: "phase delay synchrony" and "perfect synchrony" $(14,43)$. These mechanisms differ according to the degree of phase shifting, whether the full timing adjustment occurs immediately during one signal period or gradually over many, and whether the signaler adjusts its endogenous (free-running) rhythm. Both mechanisms were first described in synchronizing insects $(66,144)$, but recent findings and reinterpretations of earlier data indicate that modified versions also exist in alternating insects and in anurans.

\section{Phase Delay Mechanisms}

PHASE DELAY SYNCHRONY Experiments with Pteroptyx cribellata, a Melanesian lampyrid which produces a $20-\mathrm{ms}$ flash at $1 \mathrm{sec}^{-1}$, provided a detailed analysis of phase delay synchrony (18). A male presented with a single isolated flash stimulus, after one of his own signals, delayed his subsequent signal by a phase angle (response phase) equivalent to the phase angle (stimulus phase) between that first signal and the stimulus (Figure 1b). If the flash stimulus was presented immediately prior to the male's signal, however, this signal remained unaffected, but his next signal was advanced by an amount (response phase) equal to the stimulus phase. Presumably, the first signal had already been triggered prior to the stimulus.

The above responses may be summarized via a phase response curve (PRC) in which response phase is regressed against stimulus phase $(62,133,144)$. PRCs obtained for $P$. cribellata have a slope $\approx 1$ and pass through the origin (Figure 2a). A parsimonious explanation for this PRC is that (a) the CNS pacemaker ascends slowly from the basal to the trigger level, $(b)$ the pacemaker descends rather steeply - but not instantaneously - to the basal level after being triggered, $(c)$ certain external stimuli instantaneously reset the pacemaker to the basal level, and $(d)$ the pacemaker resumes its free-running rhythm after being reset (Figure 1c). Thus, a stimulus such as the flash of a neighbor generates a positive phase shift (phase delay) if the stimulus phase is greater than $0^{\circ}$ but less than approximately $315^{\circ}$ (the transition phase) and a negative phase shift if between approximately $-45^{\circ}$ and $0^{\circ}$ (after the CNS pacemaker has been triggered, but prior to effector output). If two neighboring males both signal at similar rates that fluctuate little, phase delays mutually align their rhythms within a single period and synchrony ensues thereafter. When the rates differ greatly (by $>(T-t)^{-1}: T^{-1} ; 1.14: 1$ in the above case), however, the faster individual signals with its free-running rhythm while the slower one is repeatedly reset to the basal level before its signals are triggered. At a given level of intra- and inter-individual variation in signaling rate, species with transition phases closer to $360^{\circ}$ would be expected to synchronize less regularly and exhibit more frequent interruptions by alternation or solo signaling. 


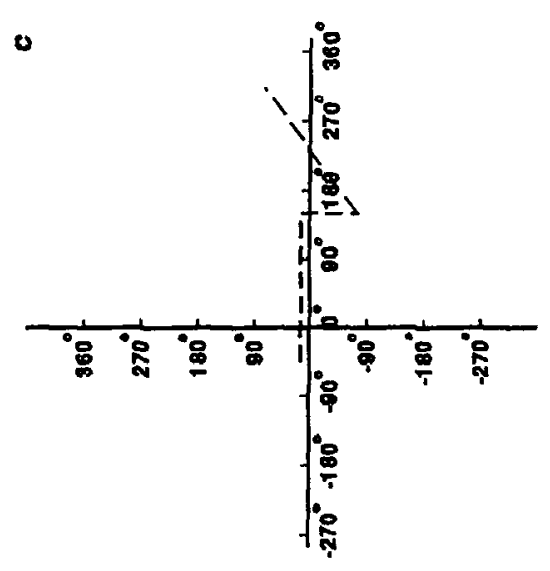

을 岁岁

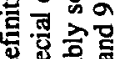
它营

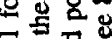
政 产类 \& 要

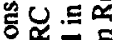

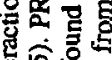
造过 몰 的可 安客
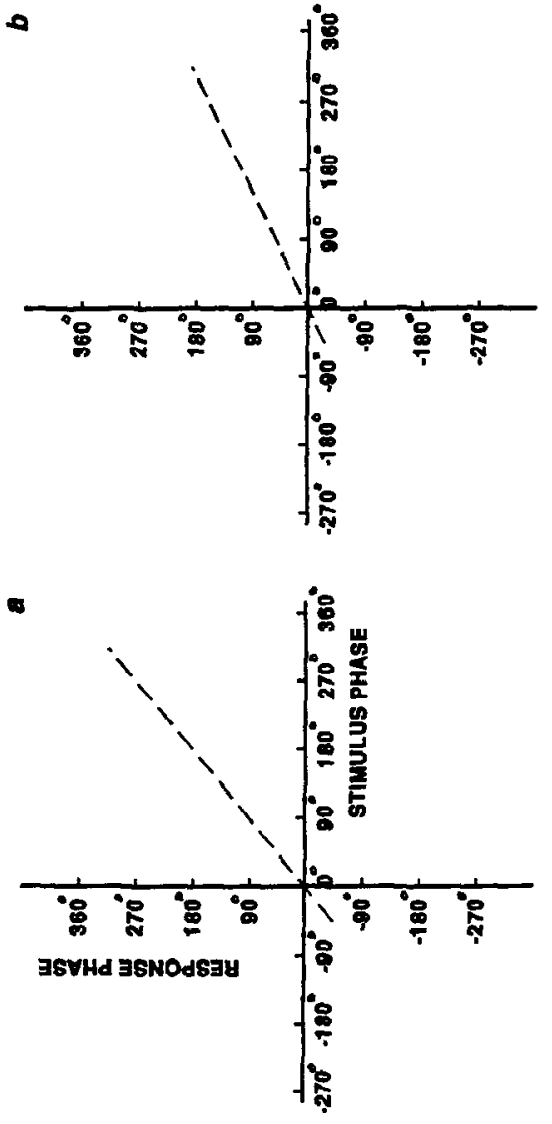

$=1$ 石果 尝题 焉证 क क्ष

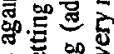
呕

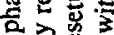

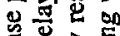
항

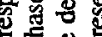
흥 至言家

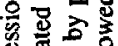
垴 政 喓 on 등 居 马ु몽 政 证 论 눈 능 ड 宛 总 . 要 + 을 11 ont 趶 这然类 
INHIBITORY RESETTING Comparable studies on various acoustic insects and anurans have revealed that the above phase delay mechanism, with several modifications, is fairly widespread. This work has been augmented significantly by recent advances in digital technology that allow acoustic signals to be synthesized and/or extensively edited in the time domain and then broadcast to signaling individuals in controlled playback experiments. In several synchronizing species of acoustic Orthoptera such playback experiments have investigated responses to regular repetitions of call stimuli and single isolated stimuli, and resetting and PRCs with slopes between 0.8-1.0 and transition phases at $220^{\circ}-300^{\circ}$ have been inferred from the results $(60,62,144)$. The species tested have signals of variable length, and this feature led to determination that a neighbor's signals, acting as external stimuli, not only reset a male's rhythm but may inhibit him as well. This modification has been termed "inhibitory resetting" (62).

In inhibitory resetting an individual's pacemaker is reset to the basal level at the onset of the stimulus, and its pacemaker remains inhibited at this level until the signal terminates. At this juncture, the pacemaker returns to the trigger level but may do so more quickly than when the stimulus is absent (Figure 1d) (62). Rapid returns are implicated by PRCs with slopes < 1 (Figure $2 \mathrm{~b}$ ) -which have been observed in various synchronizing Orthoptera $(60,62$, 144)--and they may represent an expression of the general neurophysiological phenomenon "post-inhibitory rebound" (see 130). Possibly, such rebound can occur because energy, as expended by effector output, is conserved during inhibition. A rapid return may be achieved by $(a)$ an ascending slope from the basal to the trigger level that is steeper than in the free-running condition, and/or by $(b)$ incomplete resetting to a state that is somewhat higher than the free-running basal level (Figure 1d).

PHASE SHIFT/SIGNAL LENGTH TRADE-OFF Another modification of basic phase delay synchrony seen in acoustic insects involves changes in signal length that accompany phase shifts. Playback experiments with the snowy tree cricket, Oecanthus fultoni (Orthoptera: Gryllidae), a very precise synchronizer with a transition phase at $220^{\circ}$, showed that calls are lengthened during positive phase shifts and shortened during negative phase shifts (144). This relationship is apparently a trade-off, and as such it too may reflect energetic conservation or limitation. Trade-offs between signal rate and length are reported in several acoustic species $(60,61,91,130)$, and changes in $O$. fultoni signal length may represent a special case of a general phenomenon.

PHASE DELAY ALTERNATION While early work recognized that alternation in acoustic insects and anurans was a form of interaction among rhythmic signalers, most of these studies otherwise considered alternation and synchrony 
as dissimilar events. Consequently, few attempts were made to explore the possibility that the two phenomena were generated by common mechanisms (for exceptions, see 77, 78, 91). However, recent findings and reanalyses of previously collected data suggest that modified versions of the phase delay model may regulate signal timing in many alternating species as well.

Via a series of playback experiments, it was determined that call timing in the alternating acridid grasshopper Ligurotettix planum is controlled by inhibitory resetting $(60,99)$. Analyses of responses in these tests yielded a PRC with a slope $\approx 0.6$, which indicated a pacemaker that rebounded quite rapidly after inhibition when the stimulus occurred late in the insect's period. Two individuals with equivalent free-running rhythms who adhere to this particular mechanism would be predicted to alternate. If period lengths fluctuate stochastically, however, alternation would be punctuated by occurrences of synchrony when period lengths of each individual diverge from modal values in opposite directions. Synchrony would also occur if each individual happens to begin signaling, after a long silent interval, at the same time (133). This predictionoccasional punctuation by synchrony for one or two periods-occurs in $L$. planum and in the alternating tettigoniid Pterophylla camellifolia $(3,130)$. Reinterpretations of inhibitory responses to acoustic stimuli in $P$. camellifolia $(130,134)$ and in several other alternating orthopterans $(25,70,76,79,80)$ indicate operation of an inhibitory resetting mechanism similar to that in $L$. planum. As in synchronizing orthopterans, a phase shift/signal length trade-off occurs in P. camellifolia (130).

The same modified phase delay model may also exist in many anurans, most of which, if they do engage in signal interactions, chorus in an alternating fashion (148). Various algorithms have been developed to model anuran chorusing $(88,91,100,160)$, but reexamination of data from playback experiments indicates that inhibitory resetting with a very rapid post-stimulus rebound can account for call timing in at least several species. For example, the leptodactylid frog Leptodactylus albilabris, which produces a 30-ms call at $-3.5 \mathrm{~s}^{-1}$ and both synchronizes and alternates with its neighbors, will respond to acoustic stimuli repeated 5-6 times its natural signaling rate by calling $-50 \mathrm{~ms}$ after every 4th-6th stimulus (100). Responses to slower stimulus rates are spread out over broader intervals, that still begin after 50-ms delays, but they occur after nearly every stimulus. In general, the frogs avoid calling during an interval from $20-50 \mathrm{~ms}$ after a stimulus. A "refractory period" (104) exists for $\sim 150 \mathrm{~ms}$ following the animal's call during which a stimulus has no effect on the call period. This apparently complex set of responses can be predicted, however, via a simple inhibitory resetting model (Figure 1e) in which the pacemaker is immune to external influences during the refractory period but afterwards can be reset and then rebounds rapidly. Eleutherodactylus coqui, another leptodactylid that calls at a much slower modal 
rate $\left(\sim 0.45 \mathrm{sec}^{-1}\right)$ and, in more typical anuran fashion, is a strict alternator with its (nearest) neighbors, displays similar responses (160) that are also predictable via the inhibitory resetting model in Figures 1e, 2c. In the hylid frog Pseudacris streckeri a similar model may apply; however, timing of both the first and second calls following a stimulus are influenced (88). Review of the PRCs of acoustic insects (Figure 2c), including both synchronizers and alternators $(60,62,99,144)$, suggests that brief post-call refractory periods may be present there as well.

PHASE-LOCKING IN SYNCHRONIZERS AND ALTERNATORS The ability of Leptodactylus albilabris to time its calls regularly with respect to a rapidly delivered stimulus represents a form of entrainment or phase-locking. Such locking to stimuli has been reported in other alternating and synchronizing insects $(25,76,133)$ and anurans $(160)$, although none are capable of regular interaction with a stimulus repeated as frequently as six times the natural signaling rate. Recasting signal timing in terms of inhibitory-resetting models, however, removes some of the significance often accorded to phase-locking. These models indicate that a particular phase-locking regime can result incidentally from the appropriate combination of (animal) signaling and stimulus rates and that the exceptional 1:6 locking in L. albilabris is a simple effect of a very rapid rebound in the timing mechanism. That is, were the rebound slower, the frogs would have probably been repeatedly inhibited by the high stimulus rate.

COMMON MECHANISM FOR SYNCHRONY AND ALTERNATION The value of the above interpretations is that they afford an opportunity to view a variety of signal interactions in a standard manner. This common perspective suggests that most cases of synchrony and alternation, rather than being generated by radically different mechanisms, actually represent the same basic responses which differ only in a time constant: Alternation occurs when the rebound interval $(\tau)$ following resetting (see Figure 1e) is relatively short compared with the modal signal period $(T)$, and it appears to be restricted to species with slow signaling rates. Possibly, this restriction reflects a lower bound on $\tau$ that is physiologically constrained and common to all species regardless of $T$ or signal length $(x)$ or duty cycle $(x / T)$. Such a bound would effect increased $\tau: T$ ratios at higher signaling rates. Eventually, $\tau$ would approach $T$, and regular alternation would be averted. This prediction is supported by the observation that, among insects, synchrony of acoustic (and bioluminescent) signals usually occurs in species with modal signaling rates exceeding $1 s^{-1}$ in solo, irrespective of the signal duty cycle (see 63). Conversely, most anuran signaling rates are slower than $1 s^{-1}$, and alternation is the norm in this taxon $(140,148)$. Whereas these generalizations suggest that alternation and synchrony do have 
some taxonomic affinities, both interactions are known to occur in the same genus; e.g. Platycleis (Orthoptera: Tettigoniidae) (124). The finding that within Platycleis regular acoustic synchrony occurs only in $P$. intermedia, the species with the highest signaling rate $\left(3.4 s^{-1}\right)$, lends further support to the notion that signal interaction format can often be predicted by solo rate.

Sismondo (133) addressed this issue from the perspective of PRCs, and he too demonstrated that synchrony and alternation can originate from a common mechanism, albeit not a pure phase delay one. He showed that a Southeast Asian tettigoniid, Mecopoda sp. S, that can both synchronize and alternate realized both these interactions when the slope of the PRC was lower than a critical value, but only synchrony if the slope was higher. A general model was then derived that predicted the set of conditions (stimulus and response phases) under which stable alternation (phase angle $=180^{\circ}$ ) could occur.

SYNCHRONY AND ALTERNATION AS EPIPHENOMENA Implicit in the above generalization is the concept that when synchrony and alternation are generated by a phase delay mechanism, these interactions, no matter how precise, may be epiphenomena (62; also see 3). Regular synchrony and alternation result only when neighboring individuals happen to sustain similar signaling rates. In such circumstances, individuals in a synchronizing species usually signal at low absolute phase angles $\left(0^{\circ}\right.$ to $\left.(t / T) \cdot 360^{\circ}\right)$, but they occasionally drop out of the collective display or signal in solo for a period because of the inhibition that occurs when signaling rates diverge. Thus, synchrony is a default event. Individuals in an alternating species signal in the same two phase relationships; however, the proportions are reversed-synchrony being rarebecause $\tau$ is $\ll T$. Specifically, some alternation is predicted whenever the PRC slope is $<[(T-2 t) /(T-t)]$, and at any slope below this critical value the likelihood of alternation would be proportional to $[(T-t) / T]$. In both synchrony and alternation, individuals do not signal during a "forbidden interval" ranging from $t$ to $x+\tau$ after the onset of a neighbor's signal.

Although excitation in the form of increased rates during interactive signaling occurs in some species regulated by phase delay mechanisms $(70,77,78)$, there are no firm indications in any of the species discussed above that individuals decrease their signaling rates to "accommodate" slower signalers while retaining a constant phase angle. Moreover, synchrony and alternation obviously depend on individuals signaling at consistent rates, but no data show that solo signalers reduce fluctuations in their rhythms when interacting with neighbors. Most of these natural signal interactions apparently relied on repeated resetting of the oscillator during each period rather than changes in the free-running rhythm, and $0^{\circ}$ or $180^{\circ}$ phase-locking to artificial stimuli only occurred if the stimuli were presented at particular rates.

Of special interest are several species of acoustic insects and anurans that 
exhibit both regular synchrony and alternation $(78,100,133)$. These dualities, which may be produced by pacemaker time constants close to the bifurcation values that relegate signalers to one signal interaction format or the other, enlarge the probability that synchrony and alternation per se may not be adaptive in some cases. Rather, various of these collective displays may simply represent incidental by-products of phase delay mechanisms that were not selected for because of the synchrony or alternation generated.

\section{Free-Running Oscillator Variation}

While phase delay mechanisms can account for most rhythmic signal interactions, some cases of bioluminescent and acoustic synchrony are clearly controlled in other ways. Several species of Southeast Asian lampyrids (Pteroptyx malaccae, Pteroptyx tener, Luciola pupilla) time their flashes such that phase angles very close to $0^{\circ}$ eventually result, and they do so by adjusting their oscillator periods (65). Because of this feature and the precision of the interaction, which may be partly derived from extremely stable solo rhythms, this type of proepisodic mechanism has been termed perfect synchrony (43). Perfect synchrony can occur even when neighbors do not have equivalent free-running rhythms.

Experiments with $P$. malaccae revealed a PRC with a slope only slightly greater than $0(14,65)$. By making small phase adjustments, commensurate with this PRC, over 20-40 successive periods, individuals who initially flashed at different solo rhythms converged on a single average rhythm and then remained in synchrony. After the interaction, the participants very slowly returned to their original solo rhythms. In this fashion, individual free-running rhythms can be adjusted by overall increases or decreases up to $15 \%$. A coupled-oscillator model that allows free-running rhythms to adapt slowly to each other demonstrates theoretically this attainment of perfect synchrony (43).

\section{Phase Advance Mechanisms}

The rhythmic flash synchrony occasionally seen in dense populations of some North American lampyrids (Photinus spp.) is achicved with a homoepisodic mechanism in which an individual advances its phase upon perceiving a neighbor's signal $(14,21)$. This mechanism depends on the ability to signal shortly after $(-200 \mathrm{~ms})$ a stimulus that occurs during the latter portion of the signal period. The free-running oscillator is not affected here, and the normal rhythm resumes immediately after each advanced signal. Synchrony in species with slow signaling rates $\left(\ll 1 \mathrm{sec}^{-1}\right.$ in solo) may be sustained with this mechanism, since $\tau$ is not a factor. Possibly, the synchronous chorusing observed in periodical cicadas (Magicicada cassini; $T \approx 5 \sec (4)$ is accomplished in this fashion. A simple coupled-oscillator model showed that a population of signalers obeying this phase advance mechanism will tend toward a syn- 


\section{GREENFIELD}

chronized state and will do so even if individual free-running rhythms differ slightly (136).

\section{COOPERATIVE FUNCTIONS}

The pacemaker of the human heart includes approximately 10,000 cells whose electrical rhythms are synchronized (137). Because a normal heartbeat is dependent on such synchrony, this collective neural interaction is clearly adaptive. Necessity of neural synchrony was duly recognized, and an early coupled-oscillator model was developed to describe the cardiac pacemaker (115). Is it likewise possible that some collective signal interactions are adaptations as opposed to epiphenomena and that individuals actively cooperate in achicving and maintaining particular phase relationships?

\section{Rhythmic Synchrony}

RHYTHM PRESERVATION In various rhythmically signaling species whose rates fluctuate negligibly, females only respond to male signals produced at the specific modal rate. This matching of rate and preference can hold even as rate changes with temperature in poikilothermic species (45). When female rate preference is specific as such, males who signal out of synchrony with their neighbors may prevent females from recognizing that the signaling rate of any individual male in the local group is correct $(90,144)$. Thus, a male signaling asynchronously would be committing a strongly "spiteful" act, behavior not expected because of evolutionary instability under most circumstances (86). Consequently, males may be subject to considerable selection pressure to cooperate by synchronizing, and some of the mechanisms discussed above may be adaptive.

Because receivers can more easily localize sources of bioluminescent signals than those of acoustic ones (39; but see 29), the rhythm preservation hypothesis may be a more likely factor in acoustic than bioluminescent synchrony. In fact, the function of precise synchrony in the gryllid Oecanthus fultoni has been explained as rhythm preservation, since temperature-specific signaling rates coupled with female rate preferences occur in this species (144). However, the predicted lack of responses by females presented with two or more asynchronous, but correct, calling rhythms has not been investigated. Adding to the uncertainty surrounding this hypothesis is the possibility of central neural separation of acoustic stimuli from two sources, an ability reported in another gryllid, Teleogryllus oceanicus (116). Therefore, it may be feasible, even in acoustic communication, for a female to recognize the signaling rate of a given individual amidst neighbors signaling at various phase angles, although the number of neighbors and their spatial separation could reduce this ability. 
The rhythm preservation hypothesis may yet apply to bioluminescent signaling, but on an inter-group level. If signalers are tightly clustered due to any of various ecological factors promoting spatial aggregation (see 10, 82, 122), male groups may compete to attract females distributed between the groups, although individual males would, of course, compete for females already attracted to their own group. Thus, females presented with the choice of distant male groups in which individuals either synchronize their flashes or disregard phase may orient toward the former, if perceiving a correct rhythm is essential (see 90). Thereby, intra-group male cooperation via synchrony would be selected for, since it maximizes the group's female:male ratio and female encounter rates on a per male basis. This principle could also operate for acoustic signals.

MAXIMIZATION OF PEAK SIGNAL AMPLITUDE Another way in which competition between male groups may conceivably generate synchrony derives from potential benefits of maximizing peak signal amplitude. Variations on this theme were originally proposed for lampyrids, and it was therefore termed the "beacon" effect (17). In either acoustic or bioluminescent signaling, if females are influenced more strongly by peak signal amplitude than by a time-averaged value, groups of males that synchronize would be more attractive than groups who do not. This argument does not rely on a per individual mating advantage of males signaling in larger groups per se, an advantage for which there is very little evidence among acoustic signalers [Morris et al (103) reported the only positive finding; see $(1,24,37,111,129,132,139$, and 146) for negative and equivocal results] and none among bioluminescent ones. Rather, the beacon effect as stated here only predicts that males who happen to be tightly clustered for any number of reasons should time their signals synchronously.

PERCEPTION OF FEMALE ANSWERS Courtship dialogues between male and female signalers occur in some acoustic (71) and bioluminescent $(20,26)$ insects. Typically, the answers of receptive females to long-range sexual advertisements of males are low amplitude signals produced at a specific time following the male signal. Perception by males of these responses may depend on an absence of masking by the signals of other males $(109,112)$. Therefore, males may be selected to synchronize with their neighbors, because this would eliminate the potentially obfuscating noise from the signals of these other males.

AVOIDANCE OF NATURAL ENEMIES Because male advertisement signals may be perceived by heterospecifics as well as by conspecific females, a male's risk of predation or parasitization is often increased during signaling $(22,24)$. Synchrony might reduce this risk because sound or light are thereby emitted 


\section{GREENFIELD}

from myriad directions at once. Several authors $(63,108,144)$ have suggested that a natural enemy in the midst of such a deluge would be unable to localize the source of any one signal. If this is true, cooperation via synchrony would again be selected for quite strongly. This hypothesis is a short-term analogue of the argument advanced to explain the very long-term synchrony of emergence in periodical cicadas (73) and of parturition in wildebeests (44), though predator satiation, rather than perceptual confusion, is invoked in the latter cases.

Tuttle \&: Ryan (140) provided the only evidence supporting the natural enemy avoidance hypothesis, and it does not involve thythmic signaling. They found that aggregated males in the hylid frog Smilisca sila sporadically produced synchronous calls at an average rate $=1.7 \mathrm{~min}^{-1}$. Synchrony was attained via a homoepisodic mechanism (120), and playback experiments showed that phonotactic bats preying on the frogs were attracted more frequently to asynchronous than to synchronous calls.

The most likely candidates for which any of the cooperative synchrony models may be valid are those species in which the interaction is not facultative but occurs whenever neighboring signalers are sufficiently close. This condition tends to arise when synchrony is sustained by varying the free-running oscillator, by phase delay mechanisms in which the transition phase is low, and by some homoepisodic mechanisms. Unfortunately, data that could be used to test any of the above cooperative hypotheses for synchrony have been collected only rarely. Other than the experiments on Smilisca sila, no study has indicated definitively that synchrony is cooperative. Obviously, appropriate tests on perception and orientation in receivers-female, and male, conspecifics and natural enemies-are sorely needed.

\section{Rhythmic Alternation}

RECEIVER CONFUSION Due to perceptual difficulties similar to those suggested to afflict natural enemies, female conspecifics too may be unable to locate the source of any one signal when all local signals are synchronized or overlap extensively in time. To prevent this situation, males may be selected to adjust their signaling rhythms such that alternation occurs. Among acoustic signalers this hypothesis has been tested in several anuran species, but supporting evidence has only been found in the centrolenellid frog Centrolenella granulosa (75; see 6, 114, 126, 129 for negative findings in other species). In acridid grasshoppers, which may not share with gryllids the ability to separate neurophysiologically two acoustic stimuli (see 142), reduced female phonotaxis to overlapped calls is known (98), and it may contribute, in part, to maintenance of signal alternation in Ligurotettix planum $(60,99)$.

If confusion by overlapped signals is a factor for both conspecific females 
and natural enemies, conflicting demands to both synchronize and alternate arise. Comparable dilemmas may be present in other situations, because it is conceivable that many combinations of factors could influence signal interactions. For example, competition between individual signalers, as shown in a later section, will often select for an outcome quite different from that predicted to result from competition between groups. Perhaps switching by the tettigoniid Mecopoda sp. S from synchrony to alternation (133) does represent an adaptive change in response to different influences: Factors operating specifically when neighbors are distant may select for alternation, and the resetting mechanism yielding a gradual PRC is therefore adopted when males move apart.

PRESERVATION OF SIGNAL COMPONENTS Longer acoustic and bioluminescent signals are often temporally structured such that they comprise repeated components (and sub-components), commonly termed "pulses." Because features of individual components, such as pulse rate, may be more critical to females than features of entire signals $(63,108,110)$, males may be selected to alternate because of limitations on the precision of their ability to adjust pulse timing. That is, were neighboring males to overlap signals, they would probably be unable to make the fine adjustments necessary to align temporally (synchronize) the pulses comprising their signals. Schwartz $(126,129)$ obtained support for this hypothesis in four-loudspeaker playback experiments conducted on several alternating anurans: Females were presented simultaneously with a pair of overlapping signals and a pair of nonoverlapping (alternated) ones. The signals comprising each pair were broadcast from loudspeakers separated by $180^{\circ}$; each of the four loudspeakers were separated by $90^{\circ}$. When pulses in the two overlapping signals were not synchronized, females oriented toward a signal from the other (alternated) pair. However, when the pulses in the overlapping pair of signals were synchronized, females no longer preferred signals from one pair of loudspeakers over the other. Therefore, female preference for alternated signals in the first experiment could not have resulted from an inability to localize overlapped calls.

The component preservation hypothesis is based on the assumption that receivers situated between two overlapped signals whose pulses are unsynchronized would perceive a pulse rate approximately twice the modal value (see 29 for this effect in bioluminescence) and remain nonresponsive. As such, component preservation is a fine-scale analogue of the rhythm preservation hypothesis, but it selects for signal alternation rather than synchrony.

MAXIMIZATION OF GROUP DUTY CYCLE If females are attracted to a distant acoustic or bioluminescent signaling source based on an amplitude value integrated over a long period of time, competition between groups of males could select for alternation between signals of males within groups. By alter- 
nating signals, males would maximize the duty cycle and root-mean-square amplitude value of the group's collective emission. The latter effect results because the combined amplitude value of $n$ synchronous, grouped signals, each of amplitude $A$, is $\leq n \bullet A$ (see 10).

\section{Unison Bouts and Sprees}

Competition between male groups for distant females may select for unison bouts and sprees due to reasons analogous to the peak amplitude and group duty cycle maximization hypotheses for rhythmic synchrony and alternation. This may be more likely for continuous signals than for rhythmically repeated ones, though. In the latter case, the collective timing effected by unison bouts and sprees may be too crude to generate the synchrony necessary for enhancing peak amplitude. As indicated in the previous section, however, the interval over which signal energy is integrated by a female receiver assessing amplitude may affect this issue critically. Unison bouts and sprees in rhythmically signaling species with longer integration time constants would be predicted to be more susceptible to this effect, because signals that do not overlap in time may yet be close enough that the peak amplitude assessed by females is enhanced.

\section{COMPETITIVE SIGNALING}

Sexual selection theory predicts that males may compete for females via signaling (151). The more obvious manifestations of such competition are the high amplitudes, long durations, and other extravagant features of many male sexual advertisement signals. Temporal interactions between the signals of neighbors may also represent such competition $(3,7,63)$, but of a less direct nature.

\section{Signal Jamming}

COMPETITIVE SYNCHRONY Competition and synchrony may appear to be incongruous activities. However, the frequency with which bouts of alternation and solo singing interrupt synchrony and the apparent failure of synchronizing individuals to slow their signaling rates while retaining constant phase angles suggest that many cases are not cooperative. As noted earlier, these noncooperative cases may represent mere epiphenomena. Nonetheless, do situations in which synchrony arises by default reflect underlying competitive interactions?

PSYCHOPHYSICS The attraction of females to male calls in certain orthopterans and anurans is influenced by a "precedence effect" in which preference is directed toward the first of two (or more) closely synchronized, but spatially 
separated signals $(40,62,85,98,135,152)$. In the tettigoniid Neoconocephalus spiza, the precedence effect will favor calls whose onsets are advanced as little as $13 \mathrm{~ms}$ in front of others (62). Preference for leaders will even override aspects of call energy such as duration and amplitude (62; also see 41), "non-arbitrary" features that may serve as female choice criteria in acoustic animals (see 68, 84). Consequently, males are strongly selected to adopt a timing mechanism that averts calling shortly after a neighbor and also relegates the neighbor to calling in this (following) role. The inhibitory resetting mechanism used by $N$. spiza meets these criteria, because a male adhering to it is inhibited from calling following a neighbor, yet during the next period he has a high probability of jamming the neighbor by calling in the leading role (or being the solo caller) owing to the rebound of his pacemaker following inhibition. If two males with similar modal calling rates both use inhibitory resetting, runs of synchrony are predicted to ensue. One male's signals will precede the other's by a short interval $(<t)$ during these runs, with the leading role passing back and forth between the males. Synchrony results because $\tau$ is $\approx$ $T$, and each male's pacemaker is triggered before the other male has called (62).

Computer simulation of the signaling controlled by inhibitory resetting showed that this mechanism is evolutionarily stable (ES) (see 93)-when compared with calling timed regardless of a neighbor's calls-provided that leading calls are more attractive than following ones (62). Thus, synchrony can be an ES outcome of a simple mechanism selected by the psychoacoustics of female choice. Different ES outcomes may be yielded by simulations of more complex situations: choruses in which three or more signalers are present, in which signalers can increase their calling rate for several successive periods, while maintaining the same long-term modal rate, or in which signalers may differ in available energy, which might lead to sustaining different maximum signaling rates or bout durations.

In Neoconocephalus spiza, the precedence effect does not result from any particular attractiveness of components of the call beginning (62). Rather, female preference may be directed toward the leading call because its sudden onset of sound, a critical feature, is not masked by the neighbor's call or occurs first and neurally inhibits the contralateral ear for $-100 \mathrm{~ms}$ (see 156 and forward masking in 133a). Such female choice could represent several types of indirect sexual selection (83). "Good genes" selection may apply if some males lead consistently and do so because of shorter $\tau$ s which may reflect higher vigor. Alternatively, arbitrary (Fisherian) selection may apply, and it may have originated in a "sensory bias" (121) that simply renders leading sounds more easily localized or evaluated as louder. The sensory bias interpretation is suggested by the occurrence of precedence effects in diverse taxa (156), including various mammals (e.g. humans) in which the effect does not 


\section{GREENFIELD}

occur in the context of female choice. Possibly, the effects are generated by common ancestral elements of processing that are conserved in neural design (see 38). Frecedence effects underline the importance of examining female choice via multichoice tests (see 36) and of considering temporal relationships between the alternative stimuli presented.

ALTERNATION Precedence effects that select for inhibitory resetting mechanisms adaptive for evading jamming by neighbors may generate collective alternation if $\tau$ is relatively short. Whether the specific outcome is synchrony or alternation may be a mere artifact of the $\tau: T$ ratio, but alternation per se may be selected for in some species in which females cannot localize synchronized calls (98). That is, competitive and cooperative pressures may select for a mechanism including both a forbidden interval following a neighbor's calls and a short $\tau$ (or a long $T$ ) averting synchrony, respectively. As in synchrony, regular alternation, a one-for-one correspondence of calls between individuals, will only ensue when the chorus participants sustain equivalent signaling rates (see 61). That there are no indications of faster individuals in alternating choruses reducing their signaling rates to match slower neighbors while retaining constant phase angles, even in species where females cannot localize synchronized calls, suggests that occurrences of strictly regular alternation are artefacts of equally vigorous individuals.

Unlike synchrony, alternation would be impossible to maintain as population density increases, unless individuals decrease their signaling rates markedly or disregard the rules of signal timing (99). Several studies of acoustic insects and anurans have investigated this problem, and the typical solution found entails ignoring all but the nearest (loudest?) one or two neighbors $(13,99$, $105,106,128)$. Thus, certain anomalous cases of simultaneous synchrony and alternation within choruses (e.g. 100) may be explained. Because nearby neighbors are likely to be a focal male's strongest competitors for females, such selective attention may be an adaptive response-in synchronizing as well as alternating species-to the predicament of being surrounded by multiple signalers. Finding that females too ignore more distant signalers when evaluating leader/follower roles or other attributes (a potential ability in Orthoptera given the existence of acoustic neurons capable of selective attention-117) would bolster this argument. Such support has been obtained in a tettigoniid (119) and a hylid frog (53), where playback experiments investigating the masking effects of chorus noise indicated that females did limit their choices as predicted.

Where local population density of signalers can be extremely high, as in anurans clustered at a breeding pond or occupying perches in a three-dimensional (arboreal) habitat, selective attention alone may not provide a male with calling time windows that are both nonoverlapping and outside forbidden 
intervals. Interactive algorithms in many anurans are characterized as phase delay mechanisms with very short $\tau s$. These mechanisms allow a male to insert his calls into the ends of short, unpredictable silent gaps in the chorus (105, 160 ). As such, they may be adaptations for averting production of overlapping (and following) calls while signaling in a dense aggregation.

The purported cases of jamming listed here all involve acoustic signaling. This may reflect constraints specific to the localization of acoustic signals discussed above. Perhaps, a leading bioluminescent flash does not mask the sudden onset of a following flash as perceived by a female receiver. Requisite experiments on precedence effects and female choice in bioluminescent signalers have not been done, however, and jamming interactions between longrange advertisement flashes cannot be ruled out.

\section{Mutual Assessment}

In his 1962 treatise on social behavior, Wynne-Edwards (155) suggested that animals chorus and exhibit other collective signaling displays to assess local density so that they can then regulate their population. While this sort of group-level interpretation has long since fallen into disfavor among behaviorists, various acoustic signal interactions are interpretable as adaptations that facilitate assessment on an individual level. This view may be particularly valid for alternated signals. It is indicated by the role of acoustic signaling in spacing $(5,12)$ and aggression $(61,143,157)$ and by the difficulties that an animal may have in perceiving a neighbor's calls during its own signaling. Evidence for the latter comes both from behavioral experiments relying on the technique of interactive playback (see 34,126 ) and from neurophysiological investigation.

INCOMPATIBILITY OF SIGNALING AND PERCEPTION Sexually advertising males in many acoustic orthopteran and anuran species space themselves regularly or maintain minimum nearest-neighbor distances via mutual assessment of calls $(5,12,105)$. In some acoustic species hearing is reduced during calling, a handicap due either to simple masking (69) or to neural (154) or biomechanical (107) devices. These devices may be adaptations that protect the animal's ears from high sound levels or that prevent self-excitation by territorial signals. Regardless of their origin, perceptual handicaps during signaling may select for avoidance of call overlap. Slower calling rates and/or interactive algorithms yielding alternation, such as phase delay mechanisms with low $\tau$ :T ratios, may be adaptations for accomplishing this and facilitating spacing. If a precedence effect in female choice is also present, this requirement for unimpaired assessment of neighbors should favor interactive mechanisms whose time constants yield alternation.

A corollary of the prediction that males avoid call overlap is that males in 


\section{GREENFIELD}

denser populations should signal more discontinuously to facilitate the monitoring of neighbors. Eiriksson (42) reported this effect in the acridid grasshopper Omocestus viridulus, and Dadour (35) found that the tettigoniid Mygalopsis marki widened gaps between its calls when intruders approached. Among Neoconocephalus tettigoniids, species that chirp, rather than buzz continuously, are those normally found in higher densities (57).

GRADED AGGRESSIVE SIGNALS Circumvention of perceptual impairment may be especially important during production of graded aggressive signals. These signals are often evaluated precisely such that the individual who does not match its rival departs or assumes a subordinate role. Precise evaluation is believed to be essential because of an expected correlation between signal parameters and resource holding potential. Studies of acoustic insects (61, 157), birds (11), and mammals (31) show that graded aggressive signals are normally alternated between rivals. Alternation proceeds on a strict one-forone basis until one individual begins to lag behind and then exits the encounter, presumably due to anticipated defeat if the contest were to continue and escalate. Failure to alternate could obviously lead to an inappropriate decision.

A group-level version of this phenomenon occurs in various mammals, and it may mediate assessment of social groups (94). Acoustic signals that are alternated between groups may indicate group size and resolve territorial boundaries accordingly, but the suggestion has been made that these choruses do not necessarily provide reliable information on the number of individuals present (67).

\section{Evasion of Detection}

Under certain competitive circumstances, nonjamming call overlap might actually be favored by the incompatibility of signaling and perception. A subordinate individual who synchronizes with a dominant neighbor may escape detection and probable eviction if he produces short signals that are completely overlapped by the longer signals of that neighbor (see 150,159 on "blind spots" in electric and acoustic communication). Synchrony of this sort would therefore be a variant form of satellite behavior. Possibly, long and short, overlapped calls exhibited by synchronizing male neighbors in the tettigoniid Neoconocephalus nebrascensis (97) represent such evasion by satellites from dominants.

\section{Courtship Disruption}

In signaling systems that include male-female courtship dialogues, the answers of receptive females present numerous opportunities for males to jam or otherwise interfere with their male neighbors via signal interactions. For example, a male who synchronizes with his neighbor may be able to "interlope" 
in the courtship between a female and that neighbor $(27,28)$. A synchronizing male might also detect the responses of a distant female to a signaling male neighbor and then interlope in their courtship. Opportunities for interloping and detection exist because a synchronizing male's signals are timed correctly for interacting with females responding to neighbors. Otte \& Smiley (112) and Buck (14) elaborate on diverse forms of these phenomena that may account for synchronous flashing in lampyrids. Analogous events involving the overlapping of calls may occur in orthopterans in which females respond acoustically (e.g. 51).

\section{Coincidence with Female Activity Periods}

SPREES The concentration of signaling within a narrow diel interval may represent males taking advantage of times when environmental conditions are particularly favorable for signal transmission and reception $(72,158)$, when receptive females are most numerous $(58,145)$, or when other activities are not possible, yet energy that could be expended on signaling remains (96). Because the transmission of sound is particularly subject to wind, various authors have argued that dawn and dusk choruses-acoustic sprees-are timed to coincide with periods of calm $(72,158)$. Diel timing of signaling may also be influenced by biotic factors such as the activity schedules of natural enemies and of heterospecifics whose signals may interfere $(56,59,119,125)$. However, observations of males initiating signaling when presented with conspecific song (141) and of individual males elevating their levels of signaling when joined by others (131) suggest that sprees may be cooperative or competitive social phenomena.

Competitively, individual males may be selected to match or exceed the signaling output of their neighbors in order to remain attractive to females. Because of the energetic cost of male signaling (see 92, 118, 123, 149) and narrow diel activity periods of females, pressures on males to match or exceed their neighbors' signaling may translate into compressed signaling periods that coincide with female activity $(48,58)$. Competition, rather than atmospheric conditions, may also explain the tendency of sprees to occur at photoperiodic transitions. Receptive females are often "gated" such that they arrive at encounter sites at certain times (145). For example, in many nocturnal insects and frogs, females may mature and enter receptivity at any time over a 24-hr period, but they do not become active until evening. As predicted, male calling in most of these animals is concentrated during the initial half of the night. Analogously, morning choruses in diurnal acoustic insects such as acridids and cicadas may reflect the gating of receptive females after sunrise (58). Bimodal morning/evening choruses also occur in a few species $(58,158)$, and these may correspond with two daily gates for receptive females. 
UNISON BOUTS AS EXPLODED SPREES If the arrival and presence of receptive females extends over a long diel interval, males may have insufficient energy to signal for the duration of female presence. To allocate their available energy optimally, males may break their signaling into bouts so that the entire interval is covered effectively. This hypothesis appears to be a valid explanation for bout calling in the hylid frog Hyla microcephala, because males store insufficient glycogen to fuel continuous calling throughout the entire female activity period (127).

Given the possibility that energy limitation generates bout calling by individuals, unison bout calling per se may then arise due to any of the processes that create collective displays. In both acoustic insects and frogs, unison bouts are often initiated repeatedly by the same individuals $(23,55,152)$. Bout leaders also tend to signal with the highest rates or longest calls. Surrounding males-who supposedly have less available energy - may signal following the bout leaders because the resulting unison bout affords an advantage to the group (and individual males) in attracting females or evading natural enemies. Followers may also evade detection by dominants and improve their chances of encountering females by calling at the same time as bout leaders. These complications may further explain why an early ES simulation of chorusing in the hylid frog Hyla regilla (113) did not fully resemble the unison bouts observed in this species.

\section{SUMMARY}

The investigation of signal interactions can open a window through which appreciation and understanding of the complex and subtle factors influencing the evolution of communication may be greatly enhanced. These interactions seem to be generated by a relatively limited number of neural mechanisms, yet the collective phenomena that we observe are diverse in format and may serve a variety of functions-or none at all! In many cases discerning these functions will require novel tests of how conspecific and heterospecific receivers perceive and evaluate signals in the field. Such tests promise to offer insight pertaining not only to signal interactions but to the fundamental roles played by phylogeny and current selective factors in constraining and shaping sexual signaling systems.

\section{ACKNOWLEDGMENTS}

A portion of the work reported in this review has been supported by NSF grant IBN-9196177, which is duly acknowledged. I am indebted to Bob Minckley, Stan Rand, the University of Kansas Bioacoustics Seminar (1991), the Smithsonian Tropical Research Institute Animal Behavior Group (1992), and the residents of the American Museum of Natural History Southwestern Re- 
search Station (1993) for valuable discussions, and to Jonathan Copeland, Bob Minckley, Josh Schwartz, and Enrico Sismondo for helpful criticisms leading to final preparation of the manuscript.

Any Annual Review chapter, as well as any article cited in an Annual Review chapter, may be purchased from the Annual Reviews Preprints and Reprints service. 1-800-347-8007; 415-259-5017; email: arpr@class.org

\section{Literature Cited}

1. Aiken RB. 1982. Effects of group density on call rate, phonokinesis, and mating success in Palmacorixa nana (Heteroptera: Corixidae). Can. J. Zool. 60:1665-72

2. Alexander RD. 1956. A comparative study of sound production in insects, with special reference to the singing Orthoptera and Cicadidae of the eastern United States. PhD thesis. Ohio State Univ., Columbus

3. Alexander RD. 1975. Natural selection and specialized chorusing behavior in acoustical insects. In Insects, Science, and Society, ed. D Pimentel, pp. 35-77. New York: Academic

4. Alexander RD, Moore TE. 1958. Studies on the acoustical behavior of seventeenyear cicadas (Homoptera: Cicadidae: Magicicada). Ohio J. Sci. 58:107-27

5. Arak A, Eiriksson T, Radesäter T. 1990. The adaptive significance of acoustic spacing in male bushcrickets Tettigonia viridissima: a perturbation experiment. Behav. Ecol. Sociobiol. 26:1-7

6. Backwell PRY, Passmore NI. 1991. Sonic complexity and mate localization in the leaf-folding frog, Afrixalus delicatus. Herpetologica 47:226-29

7. Bailey WJ. 1991. Acoustic Behaviour of Arthropods. London: Chapman \& Hall

8. Bailey WJ, Rentz DCF. 1990. The Tettigoniidae: Biology, Systematics, and Evolution. Berlin: Springer-Verlag

9. Belwood JJ, Morris GK. 1987. Bat predation and its influence on calling behavior in Neotropical katydids. Science 238:64-70

10. Bradbury JW. 1981. The evolution of leks. In Natural Selection and Social Behavior: Recent Research and New Theory, ed. RD Alexander, DW Tinkle, pp. 138-69. New York: Chiron

11. Bremond J-C, Aubin T. 1992. Cadence d'emission du chant territorial du troglodyte (Troglodytes). C.R. Acad. Sci. Paris. Ser. III. 314:37-42

12. Brush JS, Gian VG, Greenfield MD.
1985. Phonotaxis and aggression in the coneheaded katydid Neoconocephalus affinis. Physiol. Entomol. 10:23-32

13. Brush JS, Narins PM. 1989. Chorus dynamics of a neotropical amphibian assemblage: comparison of computer simulation and natural behaviour. Anim. Behav. 37:33-44

14. Buck J. 1988. Synchronous rhythmic flashing in fireflics. II. Q. Rev. Biol. 63:265 89

15. Buck J, Buck E. 1966. Biology of synchronous flashing of fireflies. Nature 211:562-64

16. Buck J, Buck E. 1968. Mechanism of rhythmic synchronous flashing of fireflies. Science 159:1319-27

17. Buck J, Buck E. 1978. Toward a functional interpretation of synchronous flashing by fireflies. Am. Nat. 112:47192

18. Buck J, Buck E, Case JF, Hanson FE. 1981. Control of flashing in fireflies. V. Pacemaker synchronization in Pteroptyx cribellata. J. Comp. Physiol. A. 144: 287-98

19. Buck J, Buck E, Hanson FE, Case JF, Mets L, Atta GJ. 1981. Control of flashing in fireflies. IV. Free run pacemaking in synchronic Pteroptyx. J. Comp. Physiol. A. 144:277-86

20. Buck J, Case JF. 1986. Flash control and female dialog repertory in the firefly Photinus greeni. Biol. Bull. 170: 176-97

21. Buck J, Hanson FE, Buck E, Case JF. 1982. Mechanism and function of synchronous flashing in the firefly Photinus pyralis. Biol. Bull. 163:398

22. Burk TE. 1982. Evolutionary significance of predation on sexually signalling males. Fla. Entomol. 65:90-104

23. Busnel M-C. 1967. Rivalité acoustique et hiérarchic chez l'ephippiger (Insect, Orthoptere, Tettigoniidea,). Z. vergl. Physiol. 54:232-45

24. Cade WH. 1981. Field cricket spacing and the phonotaxis of crickets and 
parasitoid flies to clumped and isolated cricket songs. Z. Tierpsychol. 55:365-75

25. Cade WH, Otte D. 1982. Alternation calling and spacing patterns in the field cricket Acanthogryllus fortipes (Orthoptera; Gryllidae). Can. J. Zool. 60:291620

26. Carlson AD, Copeland J. 1985. Flash communication in fireflies. Q. Rev. Biol. 60:415-36

27. Carlson AD, Copeland J. 1988. Flash competition in male Photinus macdermotti fireflies. Behav, Ecol. Sociobiol. 22:271-76

28. Case JF. 1980. Courting behavior in a synchronously flashing, aggregative firefly, Pteroptyx tener. Biol. Bull. 159: 613-25

29. Case JF. 1984. Vision in mating behaviour of fireflies. See Ref. 89, pp. 195-222

30. Case JF, Buck J. 1963. Control of flashing in fireflies. II. Role of central nervous system. Biol. Bull. 125:234-50

31. Clutton-Brock TH, Albon SD. 1979. The roaring of red deer and the evolution of honest advertisement. Behaviour 69: 145-70

32. Crawford CS, Dadone MM. 1979. Onset of evening chorus in Tibicen marginalis (Homoptera: Cicadidae). Env. Entomol. 8:1157-60

33. Cuthill IC, Macdonald WA. 1990. Experimental manipulation of the dawn and dusk chorus in the blackbird Turdus merula. Behav. Ecol. Sociobiol. 26:209

34. Dabelsteen T. 1992. Interactive playback: a finely tuned response. See Ref. 94, pp. 97-109

35. Dadour IR. 1989. Temporal pattern changes in the calling song of the katydid Mygalopsis marki Bailey in response to conspecific song (Orthoptera: Tettigoniidae). J. Insect Behav. 2:199

36. Doherty JA. 1985. Phonotaxis in the cricket, Gryllus bimaculatus DeGeer: comparisons of choice and no-choice paradigms. J. Comp. Physiol. A. 157: 279-89

37. Doolan JM, MacNally RC. 1981. Spatial dynamics and breeding ecology in the cicada Cystosoma saundersii: the interaction between distributions of resources and intraspecific behavior. J. Anim. Ecol. 50:925-40

38. Dumont JPC, Robertson RM. 1986. Neuronal circuits: an evolutionary perspective. Science 233:849-53

39. Dusenbery DB. 1992. Sensory Ecology. How Organisms Acquire and Respond to Information. New York: Freeman

40. Dyson ML, Passmore NI. 1988. Two. choice phonotaxis in Hyperolius marmoratus (Anura: Hyperoliidae); the effect of temporal variation in presented stimuli. Anim. Behav. 36:648-52

41. Dyson ML, Passmore NI. 1988. The combined effects of intensity and the temporal relationship of stimuli on phonotaxis in female painted reed frogs Hyperolius marmoratus. Anim. Behav. 36:1555-56

42. Eiriksson T. 1992. Density dependent song duration in the (grasshopper Omocestus viridulus. Behaviour 122:12132

43. Ermentrout B. 1991. An adaptive model for synchrony in the firefly Pteroptyx malaccae. J. Math. Biol. 29:571-85

44. Estes RD. 1966. Behaviour and natural history of the wildebeest (Conochaetes taurinus Burchell). Nature 212:9991000

45. Ewing AW. 1989. Arthropod Bioacoustics. Neurobiology and Behaviour. Ithaca, NY: Cornell Univ. Press

46. Feaver M. 1977. Aspects of the behavioral ecology of three species of Orchelimum (Orthoptera: Tettigoniidae). PhD thesis. Univ. Mich., Ann Arbor

47. Finke C, Prager J. 1980. Pulse-train synchronous pair-stridulation by male Sigara striata (Heteroptera, Corixidae). Experientia 36:1172-73

48. Forrest TG. 1983. Calling songs and mate choice in mole crickets. See Ref. 64, pp. 185-204

49. Fulton BB. 1934. Rhythm, synchronism, and alternation in the stridulation of Orthoptera. J. Elisha Mitchell Sci. Soc. 50:263-67

50. Galliart PL, Shaw KC. 1991. Role of weight and acoustic parameters, including nature of chorusing, in the mating success of males of the katydid, Amblycorypha parvipennis (Orthoptera: Tettigoniidae). Fla. Entomol. 74:453-64

51. Galliart PL, Shaw KC. 1991. Effect of intermale distance and female presence on the nature of chorusing by paired Amblycorypha parvipennis (Orthoptera: Tettigoniidae) males. Fla. Entomol. 74: $559-68$

52. Galliart PL, Shaw KC. 1992. The relation of male and female acoustic parameters to female phonotaxis in the katydid, (Amblycorypha parvipennis. J. Orthop. Res. 1:110-15

53. Gerhardt HC, Klump GM. 1988. Masking of acoustic signals by the chorus background noise in the green tree frog: a limitation on mate choice. Anim. Behav. 36:1247-49

54. Gibbon J, Church RM. 1992. Comparison of variance and covariance patterns in parallel and serial theories of timing. J. Exp. Anal. Behav. 57:393-406 
55. Greenfield MD. 1983. Unsynchronized chorusing in the coneheaded katydid Neoconocephalus affinis (Beauvois). Anim. Behav. 31:102-12

56. Greenfield MD. 1988. Interspecific acoustic interactions among katydids (Neoconocephalus): inhibition-induced shifts in diel periodicity. Anim. Behav. 36:684-95

57. Greenfield MD. 1990. Evolution of acoustic communication in the genus Neoconocephalus: discontinuous songs, synchrony, and interspecific interactions. See Ref. 8, pp. 71-97

58. Greenfield MD. 1992. The evening chorus of the desert clicker, Ligurotettix coquilletti (Orthoptera: Acrididae): mating investment with delayed returns. Ethology 91:265-78

59. Greenfield MD. 1993. Inhibition of male calling by heterospecific signals. Artefact of chorusing or abstinence during suppression of female phonotaxis? Naturwissenschaften 80:570-53

60. Greenfield MD. 1994. Synchronous and alternating choruses in insects and anurans: common mechanisms and diverse functions. Am. Zool. 34: In press

61. Greenfield MD, Minckley RL. 1993. Acoustic dueling in tarbush grasshoppers: settlement of territorial contests via alternation of reliable signals. Ethology 95:302-26

62. Greenfield MD, Roizen I. 1993. Katydid synchronous chorusing is an evolutionarily stable outcome of female choice. Nature 364:618-20

63. Greenfield MD, Shaw KC. 1983. Adaptive significance of chorusing with special reference to the Orthoptera. Sec Ref. 64, pp. 1-27

64. Gwynne DT, Morris GK, ed. 1983. Orthopteran Mating Systems: Sexual Competition in a Diverse Group of Insects. Boulder, Colo: Westview

65. Hanson FE. 1978. Comparative studies of firefly pacemakers. Fed. Proc. 37: 2158-64

66. Hanson FE, Case JF, Buck E, Buck J. 1971. Synchrony and flash entrainment in a New Guinea firefly. Science 174: 161-64

67. Harrington FH. 1989. Chorus howling by wolves: acoustic structure, pack size and the beau geste effect. Bioacoustics 2:117-36

68. Hedrick AV. 1986. Female preferences for male calling bout duration in a field cricket. Behav. Ecol. Sociobiol. 19:7377

69. Hedwig B. 1990. Modulation of auditory responsiveness in stridulating grasshoppers. J. Comp. Physiol. A. 167:847-56
70. Heiligenberg W. 1969. The effect of stimulus chirps on a cricket's chirping (Acheta domesticus). Z. vergl. Physiol. 65:70-97

71. Heller K-G, von Helversen D. 1986. Acoustic communication in phaneropterid bushcrickets: species-specific delay of female stridulatory response and matching male sensory time window. Behav. Ecol. Sociobiol. 18:189-98

72. Henwood K, Fabrick A. 1979. A quantitative analysis of the dawn chorus: temporal selection for communicatory optimization. Am. Nat. 114:260-74

73. Hoppensteadt FC, Keller JB. 1976. Synchronization of periodical cicada emergences. Science 194:335-37

74. Huber F. 1965. Brain controlled behaviour in orthopterans. In The Physiology of the Insect Central Nervous System, ed. JE Treherne, JWL Beament, Pp. 233-46. New York: Academic

75. Ibáñez RD. 1993. Female phonotaxis and call overlap in the neotropical glassfrog Centrolenella granulosa. Copeia 1993:846-50

76. Jones MDR. 1963. Sound signals and alternation behaviour in Pholidoptera. Nature 199:928-29

77. Jones MDR. 1964. Inhibition and excitation in the acoustic behaviour of Pholidoptera. Nature 203:322-23

78. Jones MDR. 1966. The acoustic behaviour of the bush cricket Pholidoptera griseoaptera. 1. Alternation, synchronism, and rivalry between males. J. Exp. Biol. 45:15-30

79. Jones MDR. 1966. The acoustic behaviour of the bush cricket Pholidoptera griseoaptera. 2. Interaction with artificial sound signals. J. Exp. Biol. 45:3144

80. Jones MDR. 1974. The effect of acoustic signals on the chirp rhythm in the bush cricket Pholidoptera griseoaptera. J. Exp. Biol. 61:345-55

81. Kacelnik A, Krebs JR. 1982. The dawn chorus in the great tit (Parus major): proximate and ultimate causes. Behaviour 83:287-309

82. Karban R. 1982. Increased reproductive success at high densities and predation satiation for periodic cicadas. Ecology 63:321-28

83. Kirkpatrick M, Ryan MJ. 1991. The paradox of the lek and the evolution of mating preferences. Nature 350:33-38

84. Klump GM, Gerhardt HC. 1987. Use of non-arbitrary acoustic criteria in mate choice by female gray tree frogs. Nature 326:286-88

85. Klump GM, Gerhardt HC. 1992. Mechanisms and function of call-timing in 


\section{GREENFIELD}

male-male interactions in frogs. See Ref 94, pp. 153-74

86. Knowlton N, Parker GA. 1979. An evolutionarily stable strategy approach to indiscriminate spite. Nature 279:419-21

87. Lall AB. 1993. Action spectra for the initiation of bioluminescent flashing activity in males of the twilight-active firefly Photinus scintillans (Coleoptera: Lampyridae). J. Insect Physiol. 39:12327

88. Lemon RE, Struger J. 1980. Acoustic entrainment to randomly generated calls by the frog, Hyla crucifer. J. Acoust. Soc. Am. 67:2090-95

89. Lewis T, ed. 1984. Insect Communication. London: Academic

90. Lloyd JE. 1973. Model for the mating protocol of synchronously flashing fireflies. Nature 245:268-70

91. Loftus-Hills JJ. 1974. Analysis of an acoustic pacemaker in Strecker's chorus frog, Pseudacris streckeri (Anura: Hylidae). J. Comp. Physiol. 90:75-87

92. MacNally RC. 1984. On the reproductive energetics of chorusing males: costs and patterns of call production in two sympatric species of Ranidella (Anura). Oikos 42:82-91

93. Maynard Smith J, Price GR. 1973. The logic of animal conflict. Nature 246:1518

94. McComb K. 1992. Playback as a tool for studying contests between social groups. See Ref. 94, pp. 111-19

95. McGregor PK, ed. 1992. Playback and Studies of Animal Communication. New York: Plenum

96. McNamara JM, Mace RH, Houston AI. 1987. Optimal daily routines of singing and foraging in a bird singing to attract a mate. Behav. Ecol. Sociobiol. 20:399405

97. Meixner AJ, Shaw KC. 1986. Acoustic and associated behavior of the coneheaded katydid, Neoconocephalus nebrascensis (Orthoptera: Tettigoniidae). Ann. Entomol. Soc. Am. 79: $554-65$

98. Minckley RL, Greenfield MD. Psychoacoustics of female phonotaxis and the evolution of male signal interactions. Ethol. Ecol. Evol. Submitted

99. Minckley RL, Greenfield MD, Tourtellot MK. Chorus structure in tarbush grasshoppers: inhibition, selective phonoresponse, and signal competition. Anim. Behav. Submitted

100. Moore SW, Lewis ER, Narins PM, Lopez PT. 1989. The call-timing algorithm of the white-lipped frog, Leptodactylus albilabris. J. Comp. Physiol. A. 164:309-19
101. Morin JG. 1986. "Firefleas" of the sea: luminescent signaling in marine ostracode crustaceans. Fla. Entomol. 69:10521

102. Morris GK. 1980. Calling display and mating behaviour of Copiophora rhinoceros (Orthoptera: Tettigoniidae). Anim. Behav.28:42-51

103. Morris GK, Kerr GE, Fullard JH. 1978. Phonotactic preferences of female meadow katydids (Orthoptera: Tettigoniidae: Conocephalus nigropleurum). Can. J. Zool. 56:1479-87

104. Narins PM. 1982. Behavioral refractory period in neotropical treefrogs. J. Comp. Physiol. A. 148:337-44

105. Narins PM. 1992. Biological constraints on anuran acoustic communication: auditory capabilities of naturally behaving animals. In The Evolutionary Biology of Hearing, ed. DB Webster, RR Fay, AN Popper, pp. 439-54. Berlin: SpringerVerlag

106. Narins PM. 1992. Evolution of anuran chorus behavior: neural and behavioral constraints. Am. Nat. 139:\$90-S104

107. Narins PM. 1992. Reduction of tympanic membrane displacement during vocalization of the arboreal frog, Eleutherodactylus coqui. J. Acoust. Soc. Am. 91:3551-57

108. Otte D. 1977. Communication in Orthoptera. In How Animals Communicate, ed. TA Sebeok, pp. 334-61. Bloomington: Indiana Univ. Press

109. Otte D. 1980 . On theories of flash synchronization in fireflies. Am. Nat. 116: $587-90$

110. Otte D. 1992. Evolution of cricket songs. J. Orthop. Res. 1:25-49

111. Otte D, Loftus-Hills J. 1979. Chorusing in Syrbula (Orthoptera: Acrididae). Cooperation, interference competition, or concealment? Ent. News. 90:159-65

112. Otte D, Smiley J. 1977. Synchrony in Texas fireflies with a consideration of male interaction models. Biol. Behav. 2:143-58

113. Partridge BL, Krebs JR. 1978. Tree frog choruses: a mixed evolutionarily stable strategy? Anim. Behav. 26:959-60

114. Passmore NI, Telford SR. 1981. The effect of chorus organization on mate localization in the painted reed frog (Hyperolius marmoratus). Behav. Ecol. Sociobiol. 9:291-93

115. Peskin CS. 1975. Mathematical Aspects of Heart Physiology. New York: Courant Inst. Math. Sci. New York Univ.

116. Pollack GS. 1986. Discrimination of calling song models by the cricket, Teleogryllus oceanicus: the influence of sound direction on neural encoding of 
the stimulus temporal pattern and on phonotactic behavior. J. Comp. Physiol. A. 158:549-61

117. Pollack GS. 1988. Selective attention in an insect auditory neuron. J. Neurosci. 8:2635-39

118. Prestwich KN, Walker TJ. 1981. Energetics of singing in crickets: effect of temperature in three trilling species (Orthoptera: Gryllidae). J. Comp. Physiol. B. 143:199-212

119. Römer H. 1993. Environmental and biological constraints for the evolution of long-range signalling and hearing in acoustic insects. Philos. Trans. R. Soc. Lond. B. 340:179-85

120. Ryan MJ. 1986. Synchronized calling in a treefrog (Smilisca sila). Short behavioral latencies and implications for neural pathways involved in call perception and production. Brain Behav. Evol. 29:196-206

121. Ryan MJ, Fox J, Wilczynski W, Rand AS. 1990. Sexual selection for sensory exploitation in the frog Physalaemus pustulosus. Nature 343:66-67

122. Ryan MJ, Tuttle MD, Taft LK. 1981. The costs and benefits of frog chorusing behavior. Behav. Ecol. Sociobiol. 8:27387

123. Sakaluk SK, Snedden WA, 1990. Nightly calling durations of male sagebrush crickets, Cyphoderris strepitans: size, mating and seasonal effects. Oikos $57: 153-60$

124. Samways MJ. 1976. Song modification in the Orthoptera. I. Proclamation songs of Platycleis spp. (Tettigoniidae). Physiol. Entomol. 1:131-49

125. Schatral A. 1990. Interspecific acoustic behaviour among bushcrickets. See Ref. 8, pp. 152-65

126. Schwartz JJ. 1987. The function of call alternation in anuran amphibians: a test of three hypotheses. Evolution 41:46171

127. Schwartz JJ. 1991. Why stop calling? A study of unison bout singing in a neotropical treefrog. Anim. Behav. 42: 565-78

128. Schwartz JJ. 1993. Male calling behavior, female discrimination and acoustic interference in the Neotropical treefrog Hyla microcephala under realistic acoustic conditions. Behav. Ecol. Sociobiol. 32:401-14

129. Schwartz JJ. 1994. Male advertisement and female choice in frogs: findings and recent approaches to the study of communication in a dynamic acoustic environment. Am. Zool. 34: In press

130. Shaw KC. 1968. An analysis of the phonoresponse of males of the true ka- tydid, Pterophylla camellifolia (Fabricius) (Orthoptera: Tettigoniidae). Behaviour 31:203-60

131. Shaw KC, Galliart PL, Smith B. 1990. The acoustic behavior of Amblycorypha parvipennis (Orthoptera: Tettigoniidae). Ann. Entomol. Soc. Am. 83:617-25

132. Shelly TE, Greenfield MD. 1991. Dominions and desert clickers (Orthoptera: Acrididae): influences of resources and male signaling on female settlement patterns. Behav. Ecol. Sociobiol. 28:133-40

133. Sismondo E. 1990 . Synchronous, alternating, and phase-locked stridulation by a tropical katydid. Science 249:55-58

133a. Sobel EC, Tank DW. 1994. In vivo $\mathrm{Ca}^{2+}$ dynamics in a cricket auditory neuron: an example of chemical computation. Science 263:823-26

134. Soucek B. 1975. Model of alternating and aggressive communication with the example of katydid chirping. $J$. Theor. Biol. 52:399-417

135. Stiedl O. 1991. Akusto-vibratorische verhaltensuntersuchungen an Ephippigerinen im Labor und im Biotop. PhD thesis. Philipps Univ., Marburg, Germany

136. Strogatz SH, Mirollo RE. 1990. Synchronization of pulse coupled biological oscillators. SIAM J. Appl. Math. 50: 1645-62

137. Strogatz SH, Stewart I. 1993. Coupled oscillators and biological synchronization. Sci. Am. 269(6):102-9

138. Sullivan BK. 1985. Male calling behavior in response to playback of conspecific advertisement calls in two bufonids. J. Herpetol. 19:78-83

139. Tejedo M. 1993. Do male natterjack toads join larger breeding choruses to increase mating success? Copeia 1993: 75-80

140. Tuttle MD, Ryan MJ. 1982. The role of synchronized calling, ambient light, and ambient noise, in anti-bat-predator behavior of a treefrog. Behav. Ecol. Sociobiol. 11:125-31

141. Villet M. 1992. Responses of free-living cicadas (Homoptera: Cicadidae) to broadcasts of cicada songs. J. Entomol. Soc. S. Afr. 55:93-97

142. von Helversen D. 1984. Parallel processing in auditory pattern recognition and directional analysis by the grasshopper Chorthippus biguttulus L. (Acrididae). J. Comp. Physiol. A.154: 837-46

143. Wagner WE Jr. 1992. Deceptive or honest signalling of fighting ability? a test of alternative hypotheses for the function of changes in call dominant frequency by male cricket frogs. Anim. Behav. 44:449-62 


\section{GREENFIELD}

144. Walker: TJ. 1969. Acoustic synchrony: two mechanisms in the snowy tree cricket. Science 166:891-94

145. Walker TJ. 1983. Diel patterns of calling in nocturnal Orthoptera. See Ref. 64. pp. 45--72

146. Walker: TJ. 1983. Mating modes and female choice in short-tailed crickets (Anurogryllus arboreus). See Ref. 64, pp. 240-67

147. Walker TJ. 1993. Phonotaxis in female Ormia ochracea (Diptera: Tachinidae), a parasitoid of field crickets. J. Insect Behav. 6:389-410

148. Wells KD. 1977. The social behaviour of anuran amphibians. Anim. Behav. 25: 666-93

149. Wells KD, Taigen TL. 1989. Calling energetics of the Neotropical treefrog, Hyla microcephala. Behav. Ecol. Sociobiol. 25:13-22

150. Westby GWM. 1979. Electrical communication and jamming avoidance between resting Gymnotus carapo. Behav. Ecol. Sociobiol. 4:381-93

151. West-Eberhard MJ. 1984. Sexual selection, competitive communication and species-specific signals in insects. See Ref. 89, pp. 283-324

152. Whitney CL, Krebs JR. 1975. Mate se- lection in Pacific treefrogs. Nature 255: 325-26

153. Wilson EO. 1975. Sociobiology. Cambridge, Mass: Harvard Univ. Press

154. Wolf $H$, von Helversen $O .1986$. "Switching-off" of an auditory interneuron during stridulation in the acridid grasshopper Chorthippus biguttulus L. J. Comp. Physiol. A. 158:861-71

155. Wynne-Edwards VC. 1962 . Animal Dispersion in Relation to Social Behaviour. Edinburgh: Oliver \& Boyd

156. Wyttenbach RA, Hoy RR. 1993. Demonstration of the precedence effect in an insect. J. Acoust. Soc. Am. 94:777-84

157. Young AJ. 1971. Studies on the acoustic behaviour of certain Orthoptera. Anim. Behav. 19:727-43

158. Young AM. 1981. Temporal selection for communicatory optimization: the dawn-dusk chorus as an adaptation in tropical cicadas. Am. Nat. 117:826-29

159. Zelick R. 1986. Jamming avoidance in electric fish and frogs: strategies of signal oscillator timing. Brain Behav. Evol. 28:60-69

160. Zelick R, Narins PM. 1985. Characterization of the advertisement call oscillator in the frog Eleutherodactylus coqui. J. Comp. Physiol. A. 156:223-29 


\section{CONTENTS}

Algal Nutrient Limitation and the Nutrition of Aquatic Herbivores, Robert W. Sterner and Dag O. Hessen

Genetic Architecture, Genetic Behavior, and Character Evolution, Gabriel Moreno

Molecular Approaches to Population Biology, Jeffry $B$. Mitton

UNISEXUAL FISH: Model Systems for Studying Ecology and Evolution, Robert C. Vrijenhoek

Cooperation and Conflict in the Evolution of Signal INTERACTIONS, Michael D. Greenfield

Evolutionary Biology of Human Immunodeficiency Virus, Andrew J. Leigh Brown and Edward C. Holmes

Metapopulation Dynamics and Genetics, Alan Hastings and Susan Harrison

Community Structure: Larval Trematodes in Snail Hosts, Armand M. Kuris and Kevin D. Lafferty

The Evolutionary Interaction Among Species: Selection, Escalation, and Coevolution, Geerat J. Vermeij

The Systematics of Coral Genus Acropora: Implications of New Biological Findings for Species Concepts, C. C. Wallace and B. L. Willis

A Day IN THE Life of A SeEd: Movements and Fates of Seeds and Their Implications For Natural and Managed Systems, Jeanne C. Chambers and James A. MacMahon

The Evolution of Vocalization in Frogs and Toads, $H$. Carl Gerhardt

Phylogeny of the Legume Family: An Approach to Understanding the Origins of Nodulation, Jeff J. Doyle 
Using DNA Sequences to UnRavel the Cambrian Radiation of the Animal Phyla, Rudolf A. Raff, Charles $R$. Marshall, and James M. Turbeville

Genetics and Ecology of Whales and Dolphins, A. Rus Hoelzel

Fisheries Ecology in the Context of Ecological and

Evolutionary TheOry, Kenneth T. Frank and William $C$.

Leggett

Ecology and Evolution of Reproduction in Milkweeds, Robert Wyatt and Steven B. Broyles

The Nature and Consequences of Indirect EfFects IN Ecological Communities, J. Timothy Wootton

INTEgrative ApProaches to Evolutionary Ecology: Anolis Lizards as Model Systems, Jonathan B. Losos

The Ecological Consequences of Shared Natural Enemies, $R$. D. Holt and J. H. Lawton

DiversifICATION IN AN ARID WORLD: The Mesembryanthemaceae, H.-D. Ihlenfeldt

Genetic Divergence, Reproductive Isolation, and Marine Speciation, Stephen R. Palumbi

Adaptation and Constraint in Complex Life Cycles of Animals, Nancy A. Moran

Male Parental Behavior in Birds, Ellen D. Ketterson and Val Nolan, Jr.

Relationships among Maximum Stomatal Conductance, Ecosystem Surface Conductance, Carbon Assimilation Rate, and Plant Nitrogen Nutrition: A Global Ecology Scaling Exercise, E.-Detlef Schulze, Francis M. Kelliher, Christian Körner, Jon Lloyd and Ray Leuning

INDEXES

Subject Index

Cumulative Index of Contributing Authors, Volumes 21-25

Cumulative Index of Chapter Titles, Volumes 21-25 